\title{
Studies on the Compressibility and Shear Strength Behaviour of Fly Ash and Slag Mixtures
}

\author{
Anil Kumar Sharma ${ }^{1}$. P. P. Sivapullaiah ${ }^{2}$
}

Received: 2 July 2020 / Accepted: 18 March 2021 / Published online: 9 April 2021

(c) The Author(s), under exclusive licence to Springer Nature Switzerland AG 2021

\begin{abstract}
This paper investigates on the mechanical characteristics (compressibility and shear strength) of fly ash/ground-granulated blast-furnace slag (GGBS) mixtures at various mix ratios using consolidation and direct shear tests, respectively. The consolidation studies were done at a reduced duration of load increment. The compressibility behaviour has been found to improve with increase in GGBS content. Direct shear test results showed an increase in angle of internal friction with GGBS content. Microstructural studies using SEM reveal insight information about the effect of particle morphology responsible on compressibility and shear strength behaviour. It is proposed from the findings of this investigation that fly ash/GGBS mixtures have utilisation potential in the construction of embankments or structural fill which will undergo very small settlement.
\end{abstract}

Keywords Fly ash $\cdot$ GGBS $\cdot$ Embankments $\cdot$ Compressibility $\cdot$ Shear strength

\section{Introduction}

The demand of power has increased tremendously with the rise in population and industrial development. This has led to the installation of many power plants to cope up with the present need. Majority of these power plants are run by burning coal, diesel, gas etc. known as thermal power plants (TPPs). In India, about $70 \%$ of the total power generation comes from TPPs out of which the power plants that burn coal accounts for $84 \%$ of the power produced [1]. Coalbased plants produce by-products commonly known as fly ash which consist oxides of various elements such as silica, aluminium, calcium, iron, magnesium etc. As per estimate, the fly ash production per year in India has reached 170 million tonnes (MT) in 2011-2012 [2]. The huge production of fly ash has created disposal and environmental problems. The present practice of disposal of fly ash is to dump on ash ponds, lagoons etc. which affects thousands of hectares of valuable land area [3]. As the environmental concerns gain importance, government and companies are looking for

Anil Kumar Sharma

aks.ce@nitp.ac.in

1 Department of Civil Engineering, National Institute of Technology Patna, Patna, Bihar 800005, India

2 Department of Civil Engineering, Indian Institute of Science, Bangalore, Karnataka 560012, India sustainable solutions. Although the use of fly ash in various applications such as concrete, brick making, soil-stabilisation treatment is well-recognised, still a large percentage of fly ash remain unutilised. Some applications that involve bulk usage of fly ash, include embankment construction [4], structural filling [5], construction of road sub base [6] etc. If properly designed and constructed, the material can function successfully in the above applications.

Compressibility is one of the important engineering properties that need to be considered during the construction of embankments, structural earth fills, for building sites etc. Low compressibility is desirable in embankments and similar constructions so that total or differential settlements between structures and adjacent approaches remain within acceptable limits. The stiffness of fly ash is comparable to hard clay and coefficient of volume compressibility $\left(m_{v}\right)$ value ranges between 0.1 and $0.2 \mathrm{MN} / \mathrm{m}^{2}$ [7]. Usually, settlements in compacted fly ash are very fast under the application of load [8]. Porbaha et al. [9] found that as the time elapses, hardening process continues because of pozzolanic reaction and prohibits any additional settlement. A study by Kaniraj and Gayathri [10] revealed that the coefficient of consolidation of the fly ash samples is similar to those of non-plastic silts. The compressibility of fly ash is found to be less than that of both pond ash and bottom ash [11]. Mishra and Das [12] have tried out to bring out the applicability of pond ash as an alternate material to river sand for 
stowing of mined out area in underground mines by studying the compressibility behaviour. The coefficient of secondary compression obtained from the oedometers tests performed by Tu et al. [13] on fly ash was found to be very small. The study concluded that settlement occurring due to secondary consolidation would not be of great concern for the structures founded in reclaimed fly ash. In some of the engineering problems such as design of foundation, retaining walls, embankments etc., angle of internal friction and cohesion are important shear strength parameters that are required for the design. Direct shear tests are used to predict these parameters very quickly. Fly ash is cohesionless and contains particles ranging from sand to silt size. Shear strength in fly ash is mainly attained through internal but also exhibits small amount of apparent cohesion [14]. It should be noted that in addition to the particle resistance, fly ashes also exhibit pozzolanic reactivity in the presence of water which makes them harden with time [4]. Kim and Prezzi [15] studied the shear strength properties of various US fly ashes using direct shear test and CD triaxial tests. They demonstrated that the fly ashes have shear strength properties similar to sandy soils. The test results further indicated that fly ashes not only have higher peak friction angles but also show apparent cohesion due to the development of negative pore pressures (capillary suction) in unsaturated samples. However, the saturated samples did not show any cohesion due to disappearance of capillary suction.

Potential use of fly ash is due to its pozzolanic and selfhardening properties. Still, the utilisation rate of low-lime fly ash is less due to its slow reaction rate and lower pozzolanic potential. However, this drawback can be overcome by activating it with several techniques out of which chemical activation is the most common $[16,17]$. Fly ash is usually mixed with lime or cement to enhance its pozzolanic properties in various geotechnical applications. Due to the environmental concerns and increasing cost of lime and cement, other alternatives are being tried which involves replacement of lime and cement with industrial wastes such as blast-furnace slaglike GGBS. GGBS, a by-product of the steel manufacturing industry, is latent hydraulic cement which can be effectively used as an alternative to cement. Fly ash is found to be more effective when combined with other industrial products such as slag, silica fume etc. [18]. Binary and ternary combinations of fly ash with other industrial by-products provide a more promising way of utilisation than alkaline activation [19]. Several studies have been done in which various industrial wastes have been incorporated to produce materials as an alternate to Portland cement [20-23]. This would be a creative solution to save our depleting resources such as lime stone that is required for manufacture of cement and hydrated lime.

When fly ash and GGBS mixtures has to be promoted as construction materials, evaluation of consolidation and shear strength properties are of great importance. In this paper, it is proposed to study the compressibility and shear strength behaviour of mixtures of fly ash and GGBS for their possible utilisation in embankments, surcharge fills etc. among various geotechnical applications. This will help in understanding the optimised amount of both the materials for its beneficial and economical utilisation.

\section{Materials and Methodology}

\section{Raw Materials}

The materials used in the present investigation were fly ash and GGBS. Fly ash was collected from Raichur thermal power plant which is situated in Raichur district of Karnataka state, India. GGBS was provided by a ready mix concrete plant owned by L\&T in Bangalore. They are using GGBS as partial replacement for cement in the ready mix concrete. The physical properties of fly ash and GGBS were determined and are presented in Table 1. It is noticed from the particle size distribution curves that GGBS includes mainly silt sized particles; whereas, fly ash is comprised of particles ranging between fine sand and silt.

The elemental composition and morphology of fly ash and GGBS were studied by SEM/EDAX analysis using FEI ESEM Quanta 200. The SEM micrograph shows that fly ash particles exhibiting a smooth spherical surface while the corresponding EDAX spectra indicate the presence of $\mathrm{O}, \mathrm{Al}$ and $\mathrm{Si}$ atoms in majority with minor portion of $\mathrm{Ca}$ atoms (Fig. 1). Fly ash is usually composed of sphericalshaped particles known as cenospheres [24]. GGBS particles are angular in shape with sharp edges and the EDAX spectra reveal the presence of $\mathrm{Ca}$ atoms in majority (Fig. 2). $\mathrm{Ca} / \mathrm{Si}$ ratio of fly ash and GGBS was found to be 0.09 and 2.40, respectively, through EDAX analysis. It indicates that

Table 1 Physical properties of fly ash and GGBS

\begin{tabular}{lll}
\hline Properties & Materials \\
\cline { 2 - 3 } & Fly ash & GGBS \\
\hline Colour & Grey & Whitish \\
Specific gravity & 2.15 & 2.84 \\
Particle size distribution & & \\
Sand fraction (\%) & 24 & - \\
Silt fraction (\%) & 74 & 99.7 \\
Clay fraction (\%) & 2 & 0.3 \\
Liquid limit (\%) & 32 & 40 \\
Plastic limit (\%) & Non-plastic & Non-plastic \\
Plasticity index (\%) & Non-plastic & Non-plastic \\
Optimum moisture content (OMC, \%) & 22 & 22 \\
Maximum dry unit weight (MDU, kN/m ${ }^{3}$ ) & 12.46 & 15.80 \\
\hline
\end{tabular}


Fig. 1 SEM/EDAX analysis of fly ash

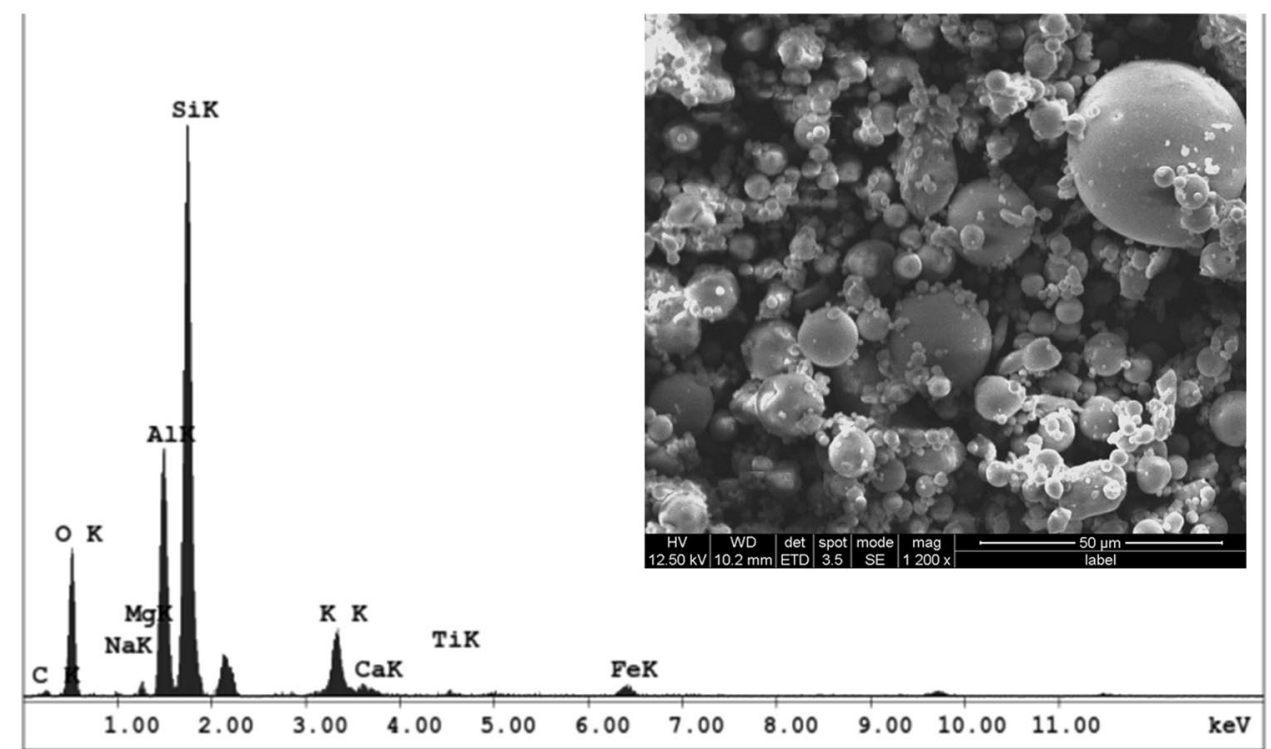

Fig. 2 SEM/EDAX analysis of GGBS

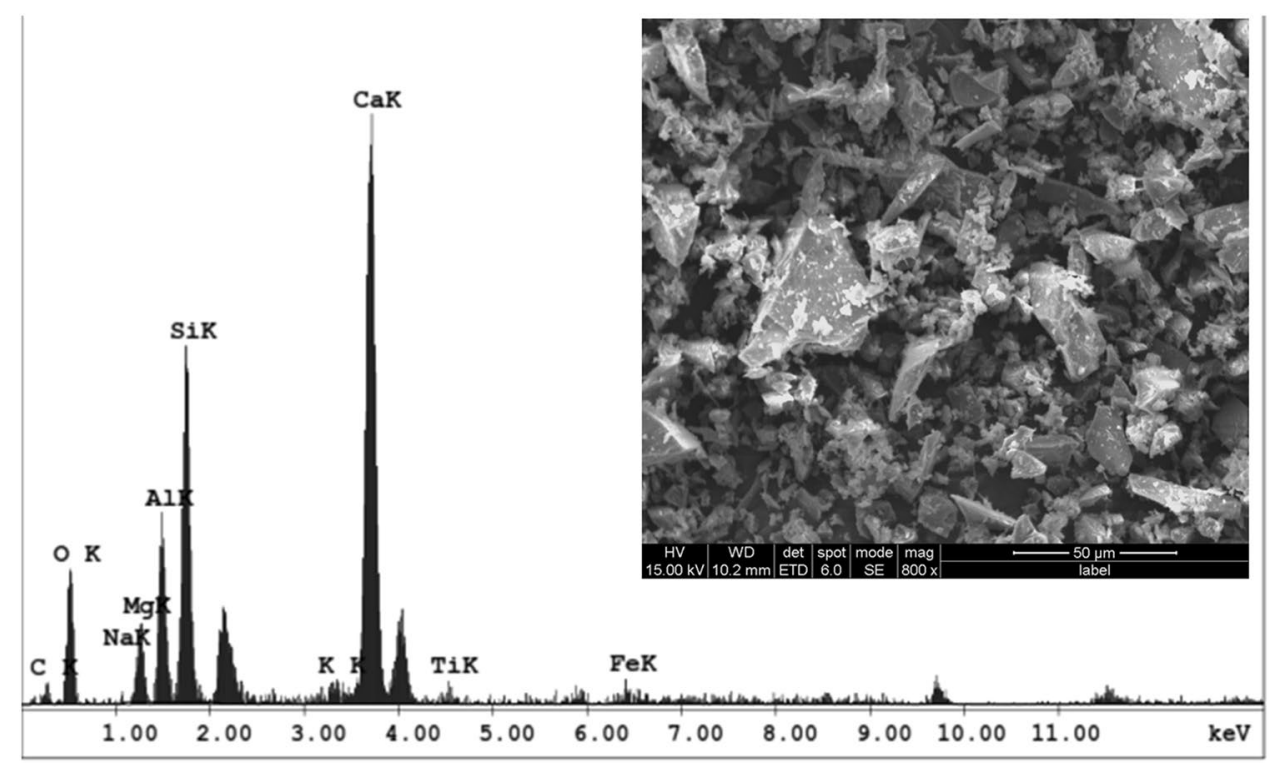

calcium content in fly is very low but contains sufficient amount of silica which is just opposite in case of GGBS. These materials, if utilised in combination with each other, can be more productive than used individually since each material can supply adequate lime or silica to encourage the pozzolanic reactions.

\section{Experimental Methodology}

\section{One-Dimensional Consolidation Tests}

The consolidation characteristics of the mixture of fly ash and GGBS at different proportions were determined using one-dimensional consolidation tests as per IS:2720 (part-15)
[25]. The amount of GGBS content was ranged between 10 and $40 \%$ of the dry weight of the mix. The samples were compacted in the consolidation rings at respective values of OMC (optimum moisture content) and MDU (maximum dry unit weight) of mixes. The OMC and MDU of the mixes were obtained from mini compaction test developed by Sridharan and Sivapullaiah [26]. The compaction characteristics of different fly ash/GGBS mixes are given in Table 2.

The requisite quantity of water was added to the dry mass of the mix to achieve optimum conditions and then transferred into consolidation rings of $60 \mathrm{~mm}$ diameter and $20 \mathrm{~mm}$ thickness after proper mixing. The samples were then remoulded inside the ring by statically pressing with a 5-mm thick spacer disc to maintain the thickness of the specimen as $15 \mathrm{~mm}$. The specimen was covered with filter papers from 
Table 2 OMC and MDU of fly ash/GGBS mixtures

\begin{tabular}{lll}
\hline GGBS $(\%)$ & OMC $(\%)$ & MDU $\left(\mathrm{kN} / \mathrm{m}^{3}\right)$ \\
\hline 0 & 22 & 12.46 \\
10 & 21 & 12.75 \\
20 & 21 & 13.15 \\
30 & 22 & 13.44 \\
40 & 23 & 13.83 \\
100 & 22 & 15.79 \\
\hline
\end{tabular}

both sides and then placed between two porous stones. After assembling the consolidometer, it was placed in the loading device and pressure was applied. A seating load of $6.25 \mathrm{kPa}$ was initially applied and inundated with water to make it saturate. After saturation, loading of the samples started at load increment ratio of unity till it reached $800 \mathrm{kPa}$. At first, fly ash and GGBS samples were subjected to two different duration of load increment i.e. $24 \mathrm{~h}$ and $30 \mathrm{~min}$. Having found that the difference of the vertical stress-strain behaviour was very minimal, the fly ash/GGBS mixture samples, henceforth, were tested for $30 \mathrm{~min}$ load duration only.

\section{Minimum Duration for Load Increment}

To minimise the duration of testing, it is proposed to establish the minimum duration for each load increment. Almost all the standard methodology generally adopts $24 \mathrm{~h}$ interval for load increment in consolidation test which is considered as sufficient enough for the completion of the primary consolidation [25, 27, 28]. But for non-plastic materials such as fly ash, the consolidation process is very fast as compared to natural soils and requires very less time period for the increment of higher loads. For compressibility studies of soils, Sridharan et al. [29, 30] suggested rapid method of consolidation test in which load can be applied just after the desired percentage of consolidation is attained. They also found that reactivity of lime in montmorillonite soils was higher that resulted in the increased compression index values than that of kaolinite soils. Fly ash and GGBS are pozzolanic materials and strength may develop due to development of cementitious compounds if the conventional approach of $24 \mathrm{~h}$ load increment is applied. Hence, actual behaviour and the consolidation properties will not be reflected at this duration (i.e. $24 \mathrm{~h}$ ) of load increment [31]. Minimising the duration of load increment could save time and produce faster results. The consolidation parameters such as coefficient of consolidation $\left(c_{v}\right)$, the coefficient of volume compressibility $\left(m_{v}\right)$ and the coefficient of permeability $(k)$ can be obtained easily and would help the geotechnical engineers to predict the settlement behaviour of such materials used in the construction of fills, embankments etc.

\section{Direct Shear Tests}

The direct shear test has been carried out as per Indian standard code IS:2720 (Part-13) [32] under unsaturated conditions. The direct shear test apparatus consists of a square box split into two halves. The dimension of the direct shear mould was measured and the amount of material required for each test was calculated based on the maximum dry unit weights. The dry mass of sample was thoroughly mixed with predetermined amount of water with the help of spatula. The wet mix of the soil samples was then transferred to the shear mould in smooth layers. A constant normal load was applied vertically on the sample through inside the mould. Horizontal load was then increased at constant rate to the upper half of the mould till the shear failure started to begin along the intersection. The applied lateral load and the induced strain were recorded at given internals. The test was usually continued till a shear strain of $10 \%$ is reached. The graph of shear stress vs. shear strain at different normal stress was plotted using the recorded readings. In addition, plotting was done with normal stress values on the $x$-axis with their respective peak shear stresses on the $x$-axis. After the linear curve fitting of the plot, cohesion was taken as the intercept of the trend line on $y$-axis; whereas, the slope of the trend line gave peak friction angle.

In this study, the tested samples were designated as per the following: FA symbol is used for fly ash and GGBS refers to ground granulated blast-furnace slag. The number preceding the symbols represents their respective percentages. For example, 70FA30GGBS denotes sample with $70 \%$ fly ash and $30 \%$ GGBS content.

\section{Results and Discussions}

\section{Effect of Duration of Load Increment on Stress- Strain Relationship}

Figures 3 and 4 show the one-dimensional compressibility plots of fly ash and GGBS, respectively, at duration of load increment of $24 \mathrm{~h}$ and $30 \mathrm{~min}$. It is noticed that onedimensional compression curves with different duration of load increment does not show much difference in the compressibility characteristics of both the materials. If the small difference is neglected, the duration of $30 \mathrm{~min}$ for each load increment is sufficient to establish the consolidation behaviour of fly ash and/or GGBS. Hence, all the compressibility studies of the fly ash/GGBS mixtures have been carried out at duration of load increment of $30 \mathrm{~min}$. 


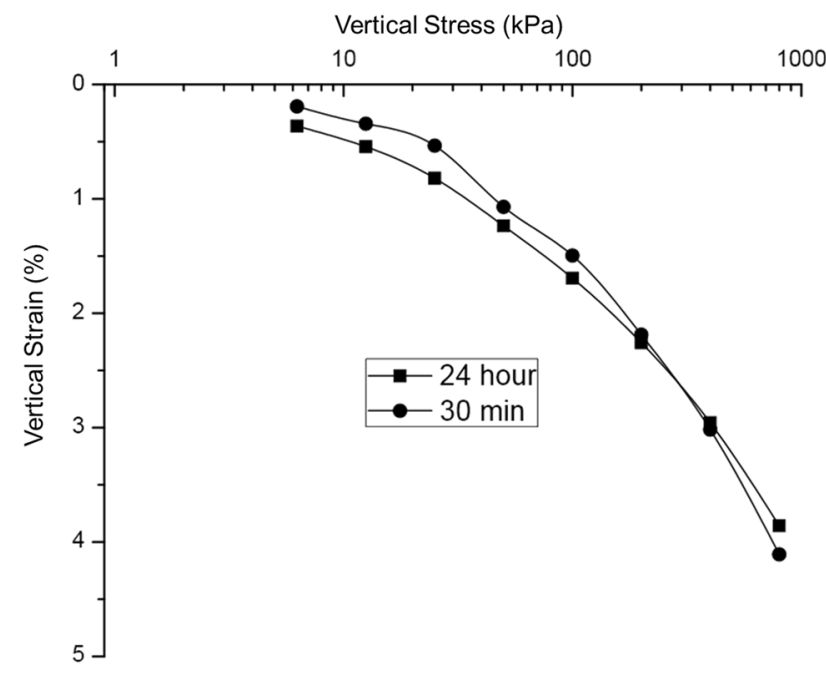

Fig. 3 One-dimensional compression curves of fly ash at different duration of load increment

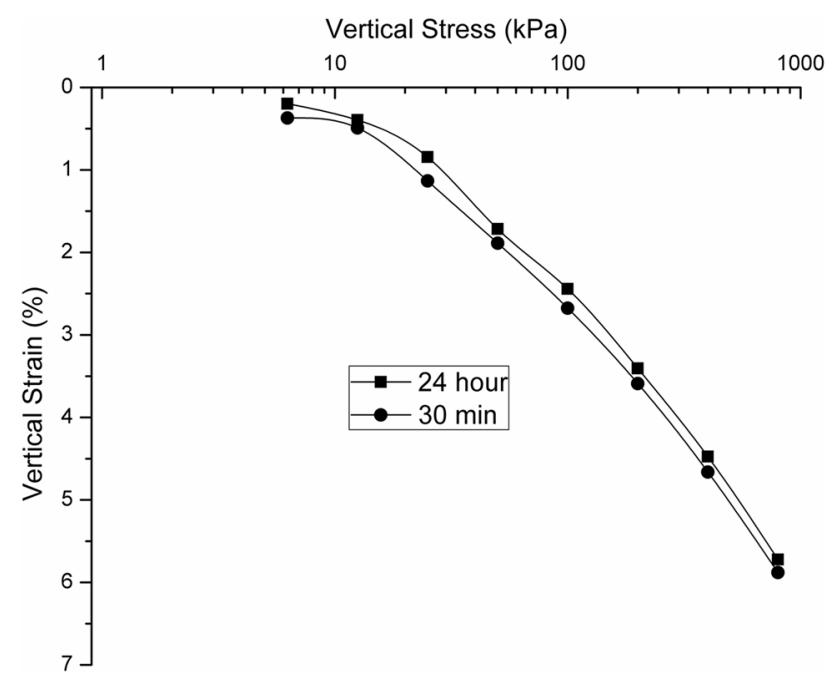

Fig. 4 One-dimensional compression curves of GGBS at different duration of load increment

\section{One-Dimensional Consolidation Behaviour of Fly Ash/GGBS Mixtures}

\section{Strain-Stress Relationships of Fly Ash/GGBS Mixtures}

The one-dimensional compressibility plots of different combination of fly ash/GGBS mixtures are shown in Fig. 5 at load increment duration of $30 \mathrm{~min}$. It can be seen that only GGBS sample shows more compressibility than pure fly ash sample. Fly ash and GGBS contain particles that differ both in shape and size. GGBS particles are angular (non-spherical) consisting of mainly silt-sized particles;

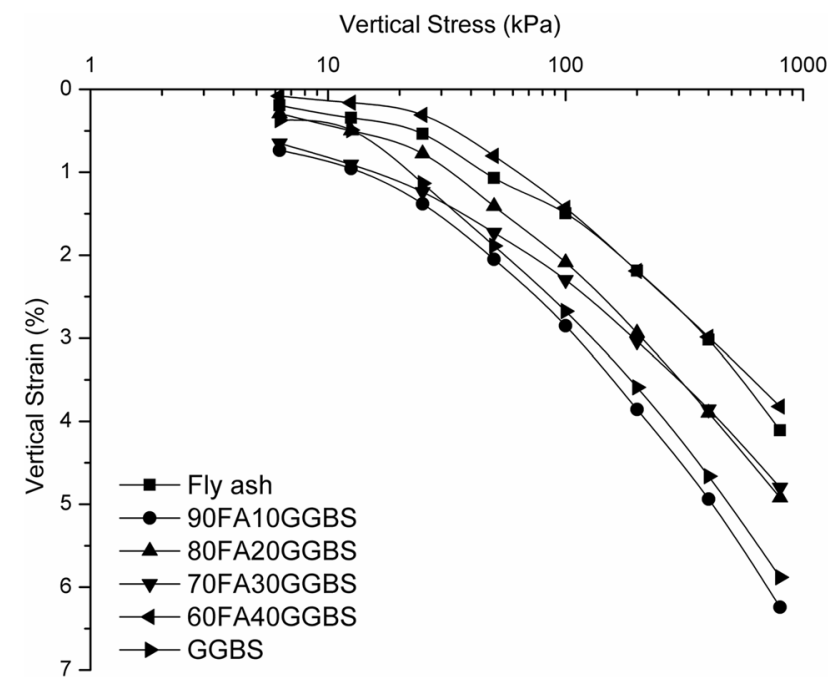

Fig. 5 One-dimensional compression curves of fly ash/GGBS mixtures

whereas, shape of majority of fly ash particles are spherical in shape. The degree of particle slippage and rearrangement of the particles which takes place during compression is found to increase as the particle size decreases [33]. This phenomenon is predominant which are composed of non-spherical particles.

Particles arrangement and interlocking in soils are the main factors that control the void ratio [34]. Hence, GGBS show higher compression than fly ash due to more slippage occurring in GGBS. But with the addition of GGBS content, the mixture becomes well-graded and shows lesser compressibility.

\section{Compression Index $\left(C_{\mathrm{c}}\right)$ and Recompression Index $\left(C_{\mathrm{r}}\right)$}

Compression index $\left(C_{\mathrm{c}}\right)$ is the slope of the linear portion of compressibility plot, void ratio $(e)$ versus effective stress plotted in logarithmic scale that shows the variation of the void ratio $(e)$ with respect to effective stress. The recompression index $\left(C_{\mathrm{r}}\right)$ is obtained from the same plot of void ratio and effective stress, but evaluated for unloading-reloading sequence. Table 3 shows the compression and recompression indices of fly ash-GGBS mix samples for 30 min duration of loading. The values of compression and recompression indices were very low for all the combination of fly ash-GGBS mix samples. It suggests that settlements on the embankments and fills (and the structures built upon these) will be immediate and minimal. Also, it reduces the time for placement of successive lifts during construction of embankment or structural fill which makes it more practically applicable in the field. 
Table 3 Compression and recompression indices of fly ash/GGBS mixtures

\begin{tabular}{lll}
\hline Sample & Compression index $\left(C_{\mathrm{c}}\right)$ & $\begin{array}{l}\text { Recompres- } \\
\text { sion index } \\
\left(C_{\mathrm{r}}\right)\end{array}$ \\
\hline Fly ash & 0.054 & 0.017 \\
90FA10GGBS & 0.071 & 0.019 \\
80FA20GGBS & 0.054 & 0.015 \\
70FA30GGBS & 0.051 & 0.017 \\
60FA40GGBS & 0.047 & 0.013 \\
GGBS & 0.069 & 0.016 \\
\hline
\end{tabular}

Table 4 Stress-strain relationship of fly ash/GGBS mixtures

\begin{tabular}{lll}
\hline Sample & \multicolumn{2}{l}{$\begin{array}{l}\text { Stress-strain relationship } R^{2} \text { coef- } \\
\text { ficient }\end{array}$} \\
\hline Fly ash & $\varepsilon=0.071 \sigma^{0.633}$ & 0.983 \\
90FA10GGBS & $\varepsilon=0.322 \sigma^{0.456}$ & 0.993 \\
80FA20GGBS & $\varepsilon=0.115 \sigma^{0.592}$ & 0.980 \\
70FA30GGBS & $\varepsilon=0.322 \sigma^{0.415}$ & 0.995 \\
60FA40GGBS & $\varepsilon=0.022 \sigma^{0.826}$ & 0.964 \\
GGBS & $\varepsilon=0.143 \sigma^{0.591}$ & 0.960 \\
\hline
\end{tabular}

\section{Constrained Modulus}

If fly ash/GGBS mixture has to be utilised as fill material, the compression of layer may be estimated by elasticity theory. Since the vertical loads applied on the embankment is of large lateral extent, the compression behaviour can be considered as one dimensional. Most commonly used parameter for the determination of settlement under one dimensional compression is the constrained modulus [15, 35, 36]. Constrained modulus (denoted as ' $D$ ') is defined as the ratio of axial stress to axial strain under confined compression [37]. It is expressed as $D=d \sigma / d \varepsilon$; where $d \sigma$ and $d \varepsilon$ is change in vertical stress and vertical strain, respectively. Constrained modulus $(D)$ is also the reciprocal of $m_{v}$.

To determine the tangent-constrained modulus at different stress level, curve fitting was first done to stress-strain curves of all the samples through power functions [38]. Power functions were then differentiated to obtain the relationship between constrained modulus and vertical stress. The relationships between one-dimensional vertical strain and vertical stress for fly ash/GGBS mix samples is shown in Table 4; whereas, relationship between vertical stress and tangent-constrained modulus is presented in Table 5.

Figure 6 shows the tangent-constrained modulus values of fly ash/GGBS mix samples on a range from zero to $200 \mathrm{kPa}$ (expected stress level for highway embankments), respectively. These figures indicate how the modulus change with increase in applied vertical stress (depth of backfill). It is
Table 5 Stress-tangent-constrained modulus relationship of fly ash/ GGBS mixtures

\begin{tabular}{ll}
\hline Sample & $\begin{array}{l}\text { Constrained } \\
\text { modulus relation- } \\
\text { ship }\end{array}$ \\
\hline Fly ash & $D=2.225 \sigma^{0.367}$ \\
90FA10GGBS & $D=0.681 \sigma^{0.544}$ \\
80FA20GGBS & $D=1.469 \sigma^{0.408}$ \\
70FA30GGBS & $D=0.748 \sigma^{0.585}$ \\
60FA40GGBS & $D=5.503 \sigma^{0.174}$ \\
GGBS & $D=1.183 \sigma^{0.409}$ \\
\hline
\end{tabular}

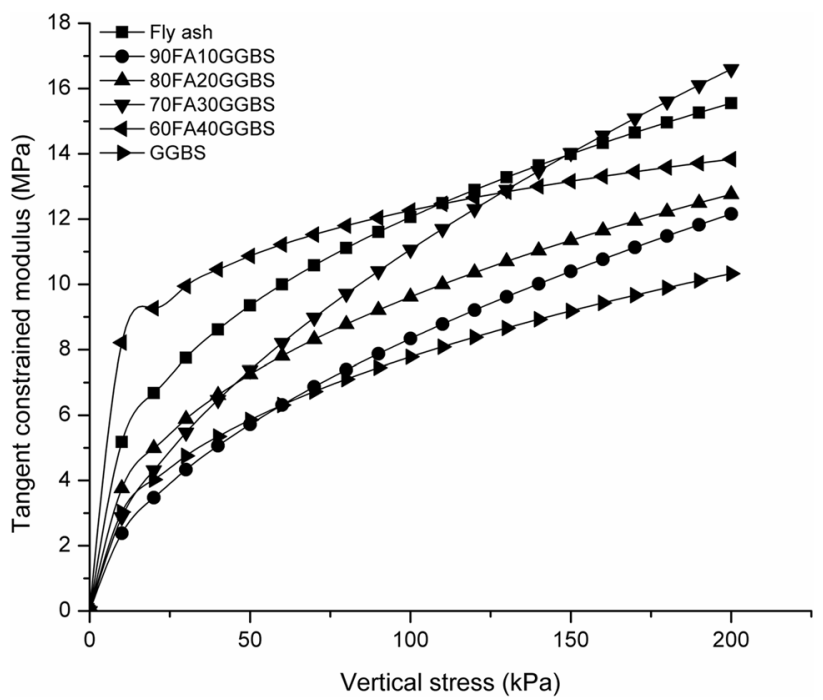

Fig. 6 Tangent-constrained moduli of fly ash/GGBS mixtures

found that tangent-constrained modulus tends to increase with increase in vertical stresses. The range of constrained modulus value suggests that the compression behaviour of fly ash/GGBS mixtures is comparable to sand. Since constrained modulus is inversely proportional to settlement, it means that the fly ash/GGBS mixtures will lead to lesser settlement when used as embankment material or structural fill.

\section{Shear Strength}

The results of direct shear tests carried out on fly ash/GGBS mix samples are presented in this section. The objective of these tests was to check the influence of GGBS amount on the shear strength characteristics of compacted fly ash/ GGBS mixtures since these materials have different particle shapes and sizes. Size and morphological characteristics of sand-like particles significantly affect the shear and interfacial shear strength [39]. It has been observed that the shear strength of dry fly ash is largely because of frictional component since it is a cohesionless, non-plastic material. 
Apparent cohesion is also present in the compacted unsaturated state but reduces to zero upon saturation [15]. Figure 7 shows the failure envelop curves of different combinations of fly ash/GGBS mixtures. Table 6 shows the shear strength parameters $(c-\varphi)$ obtained from direct shear test of fly ash/ GGBS mixtures at different proportion. The cohesion component is determined from the intercept of the line fitting the points in the shear stress versus normal stress plot.

The relatively higher values of the cohesion intercept are observed for most of the combinations of fly ash/GGBS mix samples. It could be attributed that the observed cohesion is actually the apparent cohesion arising out of capillary stresses. Angle of internal friction is found to increase with GGBS content which reveals that shear strength is also increased. In general, the capillary suction (i.e., negative pore pressure) helps to the increase the effective stress due to increase in the inter-particle contact forces.

The capillary suction increases due to decrease in the water content and particle size for unsaturated sandy soils [40]. The particle size in the fly ash/GGBS mixtures samples decreases with the increase in GGBS content since the GGBS is finer than fly ash. But the optimum water contents in the fly ash/GGBS mixtures more or less the same. Hence,
Table 6 Shear strength parameters results

\begin{tabular}{lll}
\hline Sample & Cohesion $(c), \mathrm{kPa}$ & $\begin{array}{l}\text { Friction } \\
\text { angle } \\
(\varphi),{ }^{\circ}\end{array}$ \\
\hline Fly ash & 6 & 23.30 \\
90FA10GGBS & 11 & 30.03 \\
80FA20GGBS & 2 & 35.52 \\
70FA30GGBS & 14 & 34.00 \\
60FA40GGBS & 1 & 38.02 \\
GGBS & 17 & 38.23 \\
\hline
\end{tabular}

as a result the angle of internal friction increases due to the development of higher capillary suction and higher strength is observed. Sridharan et al. [41] have conducted direct shear test on some of the Indian fly ashes and observed that shear strength of loose dry fly ash is mainly due to the frictional component, with negligible cohesive component. They also mentioned that the frictional component is dependent on the size of the particles. However, under partially saturated and compacted conditions, fly ash also exhibits apparent cohesion in addition to the frictional component. Awang

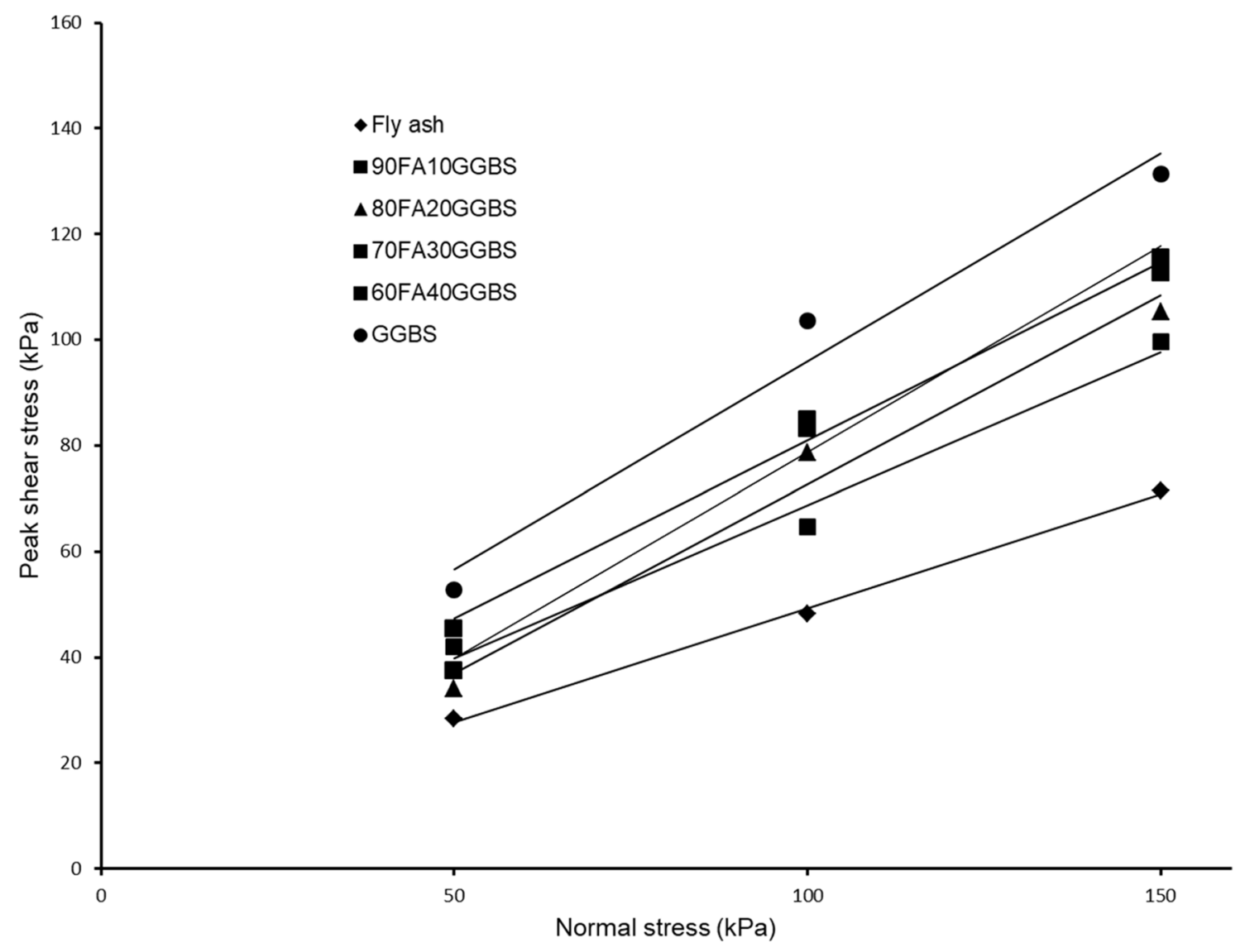

Fig. 7 Failure envelope curves of direct shear tests on fly ash/GGBS mixtures 
et al. [42] studied the shear strength behaviour of fly ash and bottom ash mixtures using direct shear test. They have demonstrated the increase in angle of internal friction of the mixtures as a result of increase in bottom ash content. They found that the angularity of the bottom ash as the main reason for the higher resistance to shearing loads.

\section{Microstructural Investigation}

Figure 8 shows the SEM images of the different mix proportions of fly ash and GGBS mixture for the sample obtained from consolidation test. The SEM images in Fig. 8a show that with the addition of $10 \%$ GGBS, the majority of particles are fly ash which are smooth surface spheres while the presence of GGBS particles are not clearly seen. The smoother fly ash particles can easily roll over each under the action of load [43]. The contact between the particles is found to increase with the increase in GGBS content which results in the increase of the frictional resistance (Fig. 8b, c). With the addition of $40 \%$ GGBS content, an aggregated microstructure is seen which is also found to be denser (Fig. 8d). Agglomeration of the fine GGBS particles and sticking to coarser fly ash particles are noticed in the SEM image. The agglomeration of fly ash and GGBS particles improves the overall microstructure offers more resistance to compression. The addition of GGBS to fly ash obviously reduces the particle slippage and assist in the proper arrangement of the mixture. Hence, very dense mix combination may be achieved upon compaction by incorporating fly ash and GGBS which will reduce settlement-related problems when used for the construction of the embankments.
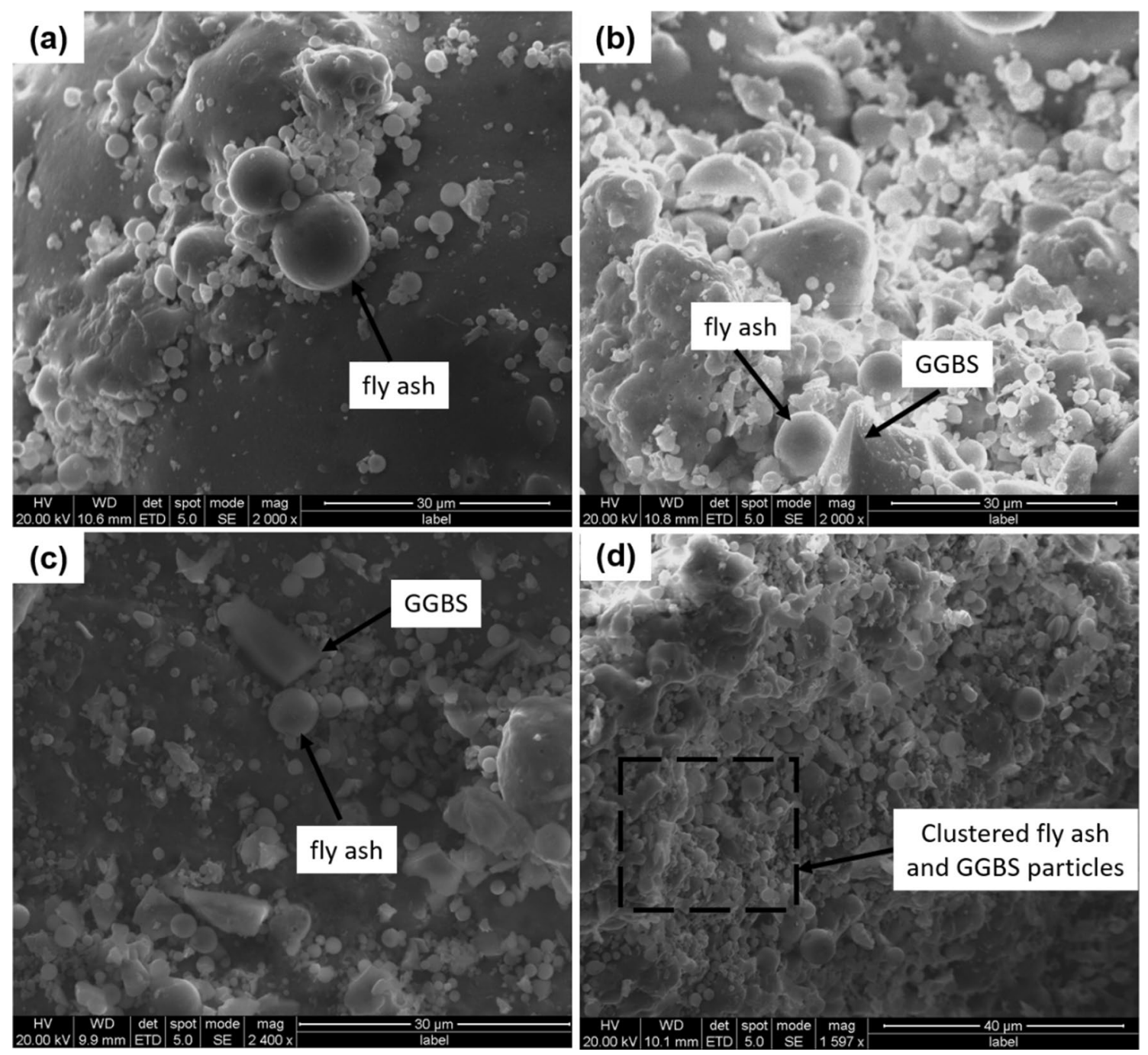

Fig. 8 SEM image of fly ash/GGBS mix samples from consolidation test a 10\% GGBS, b 20\% GGBS, c 30\% GGBS, d 40\% GGBS 


\section{Conclusions}

Based on the experimental programme carried out in this study as well as on the reported results from the literature, the following conclusions can be made:

(a) The difference between compressibility behaviours of fly ash at two different duration of load increment i.e. $24 \mathrm{~h}$ and $30 \mathrm{~min}$ has been found to be minimal and thereafter compressibility studies of fly ash/GGBS mixtures were determined with 30 min duration of load increment.

(b) The compressibility characteristics of the fly ash and GGBS are governed by the shape and size of the materials. The degree of particle slippage and rearrangement is predominant in GGBS samples during compression due to its smaller size when compared to fly ash samples. Lower values of compression and recompression values indicate that the settlement of embankments, structural fill constructed from these materials will be very less and immediate.

(c) Higher values of the cohesion for most of the combinations of fly ash/GGBS mix samples might indicate apparent cohesion due to capillary stresses. The angle of internal friction is appeared to increase with GGBS content which confirms that shear strength is also increased.

(d) The microstructural study using SEM confirms the development of a dense matrix resulting in reduced compressibility but increased shear strength. Use of combination of fly ash/GGBS can be more advantageous over using fly ash alone in construction of embankments, stowing of mines, structural fills etc.

One of the advantages of this proposed method of rapid testing is that these can give faster results and the chances of occurrence of errors are also minimised compared to traditional loading pattern ( $24 \mathrm{~h}$ load increment). For sand and silt sized materials such as fly ash and GGBS, the settlement is relatively faster than soils and there won't be much effect on the consolidation parameters. This will not only save time and effort but will also help the geotechnical engineers to predict the amount of settlement occurring in the embankment, fills etc. constructed with such materials. More accurate strength tests such as triaxial tests need to be done which will better specify the materials shear strength properties. The dynamic behaviour of material mixtures also needs to be studied by performing dynamic tests such as cyclic triaxial tests etc. Moreover, evaluating the properties of such materials which will assess their performance in the actual field conditions is required which will guarantee the materials ability to perform under actual service conditions.
Author contribution AKS designed and performed the experiments; PVS was involved in supervising the findings of the work. AKS drafted the manuscript. All the authors analysed and reviewed the results and approved the final version of the manuscript.

Funding No funding was received for conducting this study.

\section{Declarations}

Conflict of interests The authors declare that they have no conflict of interest.

\section{References}

1. Dhadse S, Kumari P, Bhagia L (2008) Fly ash characterization, utilization and Government initiatives in India: a review. J Sci Ind Res 67:11-18

2. Chatterjee AK (2011) Indian fly ashes: their characteristics and potential for mechanochemical activation for enhanced usability. J Mater Civ Eng 23(6):783-788

3. Das SK (2006) Geotechnical properties of low calcium and high calcium fly ash. Geotech Geol Eng 24(2):249-263

4. Gray DH, Lin Y-K (1972) Engineering properties of compacted fly ash. J Soil Mech Found Div 98:361-380

5. DiGioia AM, Nuzzo WL (1972) Fly ash as structural fill. J Power Div 98(1):77-92

6. Mohanty S, Chugh Y (2006) Structural performance monitoring of an unstabilized fly ash-based road subbase. J Transp Eng 132(12):964-969

7. Barber EG, Jones GT, Knight PG, Miles H (1972) Fly ash utilisation. CEGB, London

8. Cabrera J, Braim M, Rawcliffe J, Braunton P, Middleton W, Jones C, et al. (1984) The Use of Pulverized Fuel Ash for the Construction of structural Fills Conference Proceedings of Ashtech' 84 Second International Conference on Ash Technology and Marketing, Barbican Centre, London; September 16-21

9. Porbaha A, Pradhan T, Yamane N (2000) Time effect on shear strength and permeability of fly ash. J Energy Eng 126(1):15-31

10. Kaniraj SR, Gayathri V (2004) Permeability and consolidation characteristics of compacted fly ash. J Energy Eng 130(1):18-43

11. Pandian N (2013) Fly ash characterization with reference to geotechnical applications. J Indian Inst Sci 84(6):189

12. Mishra DP, Das SK (2012) One-dimensional consolidation of sedimented stowed pond ash. Geotech Geol Eng 30(4):685-695

13. Tu W, Zand B, Butalia TS, Ajlouni MA, Wolfe WE (2009) Constant rate of strain consolidation of resedimented class F fly ash. Fuel 88(7):1154-1159

14. Pal SK, Ghosh A (2009) Shear strength behaviour of Indian fly ashes. In: Indian geotechnical conference: geotechnics in infrastructure development (GEOTIDE), Guntur, India, 17-20 December, vol 1, pp 18-22

15. Kim B, Prezzi M (2008) Evaluation of the mechanical properties of class-F fly ash. Waste Manag 28(3):649-659

16. Shi C, Day RL (1995) Acceleration of the reactivity of fly ash by chemical activation. Cem Concr Res 25(1):15-21

17. Shi C, Day RL (2000) Pozzolanic reaction in the presence of chemical activators: part I. Reaction kinetics. Cem Concr Res 30(1):51-58 
18. Pavlenko S (1994) Structure formation of slag ash concrete on the basis of high-calcium fly ash and silica fume. Mater Struct 27(7):401-407

19. Winnefeld F, Leemann A, Lucuk M, Svoboda P, Neuroth M (2010) Assessment of phase formation in alkali activated low and high calcium fly ashes in building materials. Constr Build Mater 24(6):1086-1093

20. Kamon M, Nontananandh S (1991) Combining industrial wastes with lime for soil stabilization. J Geotech Eng 117(1):1-17

21. Karakurt C, Topçu İB (2011) Effect of blended cements produced with natural zeolite and industrial by-products on alkali-silica reaction and sulfate resistance of concrete. Constr Build Mater 25(4):1789-1795

22. Li G, Zhao X (2003) Properties of concrete incorporating fly ash and ground granulated blast-furnace slag. Cem Concr Compos 25(3):293-299

23. Singh M, Garg M (1999) Cementitious binder from fly ash and other industrial wastes. Cem Concr Res 29(3):309-314

24. Goodarzi F, Sanei H (2009) Plerosphere and its role in reduction of emitted fine fly ash particles from pulverized coal-fired power plants. Fuel 88(2):382-386

25. IS:2720 (Part-15). Methods of test for soils. Part 15 (1986) Determination of consolidation properties. Bureau of Indian Standards, New Delhi

26. Sridharan A, Sivapullaiah PV (2005) Mini compaction test apparatus for fine grained soils. Geotech Test J 28(3):240-246

27. ASTM D2435/D2435M-11 (2020) Standard Test Methods for One-Dimensional Consolidation Properties of Soils Using Incremental Loading. ASTM International, West Conshohocken

28. BS:1377 Part 5 (1990) British standard methods of tests for civil engineering purposes: determination of consolidation characteristics. British Standards Institution, London

29. Sridharan A, Nagaraj H, Srinivas N (1999) Rapid method of consolidation testing. Can Geotech J 36(2):392-400

30. Sridharan A, Sivapullaiah PV, Stalin VK (1994) Effect of short duration of load increment on the compressibility of soils. Geotech Test J 17(4):488-496

31. Moghal AAB, Sivapullaiah PV (2011) Effect of pozzolanic reactivity on compressibility characteristics of stabilised low lime fly ashes. Geotech Geol Eng 29(5):665-673
32. IS:2720 (Part-13) (1986) Methods of test for soils. Part 13: direct shear test. Bureau of Indian Standards, New Delhi

33. York P (1978) Particle slippage and rearrangement during compression of pharmaceutical powders. J Pharm Pharmacol 30(1):6-10

34. Rodriguez J (2013) Importance of the particle shape on mechanical properties of soil materials (Doctoral dissertation, Luleå tekniska universitet)

35. Huang W-H, Lovell C (1990) Bottom ash as embankment material. ASTM special technical publication. Int J Rock Mech Min Sci Geomech Abstr 28(6):A341

36. Kim B, Prezzi M, Salgado R (2005) Geotechnical properties of fly and bottom ash mixtures for use in highway embankments. J Geotech Geoenviron Eng 131(7):914-924

37. Lambe TW, Whitman RV (2008) Soil mechanics SI version. Wiley

38. Carrier WD (2000) Compressibility of a compacted sand. J Geotech Geoenviron Eng 126(3):273-275

39. Vangla P, Latha GM (2015) Influence of particle size on the friction and interfacial shear strength of sands of similar morphology. Int J Geosynth Ground Eng 1(1):6

40. Likos WJ, Lu N (2004) Hysteresis of capillary stress in unsaturated granular soil. J Eng Mech 130(6):646-655

41. Sridharan A, Pandian NS, Srinivasa RP (1998) Shear strength characteristics of some Indian fly ashes. Proc Inst Civ Eng Ground Improv 2(3):141-146

42. Awang AR, Marto A, Makhtar AM (2011) Geotechnical properties of Tanjung Bin coal ash mixtures for backfill materials in embankment construction. Electron J Geotech Eng 16:1515-1531

43. Pant A, Ramana G, Datta M (2019) Stick-slip behavior of dry fly ash. Part Sci Technol 38:1-12. https://doi.org/10.1080/02726351. 2019.1571543

Publisher's Note Springer Nature remains neutral with regard to jurisdictional claims in published maps and institutional affiliations. 